\title{
Uma alternativa de arrecadação emergencial: os empréstimos compulsórios
}

\author{
An emergency revenue collection alternative: compusory loans
}

William Eufrasio Nunes Pereira

Universidade Federal do Rio Grande do Norte

\author{
André De Souza Dantas Elali \\ Universidade Federal do Rio Grande do Norte
}

Resumo O presente trabalho tem como objetivo geral apresentar os empréstimos compulsórios com uma alternativa de arrecadação emergencial dada a crise econômica, social e de saúde vivenciada no Brasil. Considerando as dificuldades de aumentar a carga tributária em um período de crise política e uma estrutura tributária regressiva, constata-se a dificuldade do Estado em ampliar suas receitas para fazer frente às novas despesas da máquina pública. O contexto de fundo da defesa do empréstimo compulsório como alternativa viável ocorre em um momento de crise econômica acentuada pela crise política e radicalizada pela crise na saúde. Neste paper procura-se mostrar, como alternativa rápida e viável, o empréstimo compulsório que, politicamente, não encontraria resistências devido à legislação vigente sobre a questão encontrar-se consolidada. Para proporcionar a visão analítica e crítica aqui exposta, utilizou-se como meios de pesquisa essencialmente a pesquisa bibliográfica, a partir do levantamento de referenciais dos teóricos de relevância na área. A conclusão de todo o exposto girou em torno do reconhecimento legítimo e viável dessa alternativa emergencial em momento de crise profunda, de diversas dimensões enfrentadas pela nação brasileira.

Palavras-chave: Direito tributário; Tributos; Empréstimo compulsório; Crise eCoNÔMICA; PANDEMIa.

ABSTRaCr This present work has as general objective to present the compulsory loans with an alternative of emergency collection given the economic, social and health crisis experienced in Brazil. Considering the difficulties of increasing the tax burden in a period of crisis, the political crisis and a regressive tax structure, the State finds it difficult to expand its revenues to face the new expenses of the public sector. The background context of the defense of compulsory lending as a viable alternative occurs at a time of economic crisis accentuated by political crisis and radicalized by the health crisis. This paper seeks to show compulsory lending as a quick and viable alternative, which would not politically encounter severe political and economic resistance given the current legislation on the issue being 
consolidated. In order to provide the analytical and critical view exposed here, it was used as a means of essentially bibliographic research, based on the survey of relevant theoretical references in the area. The conclusion of all of the above revolves around the legitimate and viable recognition of this emergency alternative in a time of deep crisis, of different dimensions faced by the Brazilian nation.

Keywords: TaX law; TAXes; Compulsory loan; EConomic Crisis; Pandemic.

\section{INTRODUÇÃo}

O Brasil do século XXI ensejou um crescimento mais acelerado do que o crescimento da última década do século XX. As expectativas na primeira década foram grandes, com taxas de crescimento do investimento e do Produto Interno Bruto superiores à década anterior. Aliado a esse crescimento econômico, o aumento do emprego formal, dos salários e de outras variáveis sociais e econômicas estimularam o otimismo social. No entanto, após a crise de 2008, as expectativas começaram a sofrer abalos.

O ano de 2015 marca, do ponto de vista do PIB, o débâcle de uma política de austeridade, a qual, por dois anos consecutivos, reduziu a taxa de crescimento do PIB em mais de 3,5\% em cada ano. Nos três anos subsequentes a essa abrupta queda, o PIB também cresceu muito pouco $(1,0 \%$ em média) não revertendo a queda dos dois primeiros anos (IBGE, 2020).

O contexto de baixo crescimento é acrescido de uma pandemia mundial que potencializa o processo recessivo brasileiro. A inépcia do Governo Federal em realizar políticas anticíclicas contra a recessão junta-se ao descaso e retardamento de medidas sanitárias contra o sars-cov-2 implicando em aprofundamento da crise socioeconômica e de saúde.

As políticas econômicas anticíclicas que atenuam o impacto recessivo na economia exigem recursos financeiros de grande monta. Este trabalho visa apresentar uma alternativa jurídica prevista constitucionalmente que pode colaborar para ampliar a arrecadação emergencial para implantação dessas políticas.

O objetivo nuclear desse paper é mostrar que os empréstimos compulsórios, enquanto alternativa, não se constituem como solução, mas como paliativo de curto prazo que devido às possibilidades jurídico-constitucionais podem ser um mecanismo de rápido acionamento, dado que em momentos de crises, medidas saneadoras devem ser implantadas o mais celeremente possível.

Nesse contexto, além dessa breve introdução, o artigo apresenta uma célere digressão sobre o estado da economia pré-pandemia para, em seguida, apresentar algumas medidas e políticas implantadas pelo governo federal, mesmo que de forma retardada. Posteriormente, discorre-se sobre os empréstimos compulsórios como alternativa curtoprazista para a ampliação emergencial da arrecadação tributária. Por fim, breve comentários finais.

\section{O ESTADO E A RECESSÃo ECONÔMICA}

O fracasso da política de austeridade, imposto em 2015 pelo recém eleito governo de Dilma Rousseff, levou, após o impeachment da presidenta, à efetivação de várias refor- 
mas defendidas pelos chamados economistas de mercado que apontavam para o reforço da austeridade como forma de sair da crise, mas que efetivamente não logrou efeito nesse sentido. Ou seja, as reformas não retiraram o País da crise econômica e o impeachment não extinguiu a crise política.

O impedimento da presidente não favoreceu o retorno/crescimento do investimento privado e do PIB como pregavam os defensores da medida (CAETANO; JANKAVSKI; NOGUEIRA, 2017). Da mesma forma, a reforma trabalhista materializada na lei $13.467 / 2017$ não logrou o aumento do número de trabalhadores formais. Esperava-se a criação de mais de 6 milhões de empregos quando a reforma tributária entrasse em vigor (BRASIL, 2017).

Dados da Relação Anual de Informações Sociais (RAIS), mostram que o crescimento do emprego formal em 2018 foi de pouco mais de 349,5 mil novos vínculos, correspondendo a um aumento de $0,8 \%$ nos postos com carteira assinada no país. Em 2019 o aumento foi de pouco mais de 644 mil novos vínculos. O acumulado dos dois anos não alcança um milhão de novos vínculos, demonstrando que o resultado efetivo foi bem distante do preconizado pelos defensores da reforma.

Em 2014 o Brasil contava com mais de 49,5 milhões de vínculos formais enquanto em 2019 o estoque de vínculos era de pouco mais de 47,2 milhões, demostrando uma perda líquida de mais de dois milhões de empregos (MARTELLO, 2017. As inúmeras reformas "salvadoras" não recuperaram o emprego e nem ampliaram a renda dos trabalhadores. As reformas salvadoras apenas precarizaram os postos de trabalho em todas as dimensões.

O ano de 2019 não se mostrou promissor desde o início. Tanto é que os diversos analistas do mercado financeiro e da academia reduziram as projeções para o crescimento do PIB, praticamente toda semana no respectivo ano. As perspectivas de expansão de 2019 recuaram de 2,5\% para 1,0\% (MOTA, 2020). O PIB per capita, estava bastante inferior ao de 2014, período anterior à recessão, demonstrando que a população estava mais pobre.

$\mathrm{O}$ ano de 2020 não começa bem para a classe que vive do trabalho. Dados do IBGE mostram que a taxa de desemprego que vinha se reduzindo lentamente desde o início de 2019, apresentavam leve crescimento trimestral. Considerando o trimestre que termina em janeiro, em relação ao do mês anterior, a taxa de desemprego aumentou de 11\% para $11,2 \%$. Da mesma forma, o trimestre que termina em fevereiro em relação ao trimestre anterior apresentou um crescimento da taxa de desemprego, subindo para 11,6\%. Esses dados já mostram que 2020 não seria tranquilo e que as reformas não surtiram o efeito esperado.

Com o coronavírus e o isolamento social a partir de março, a taxa de desemprego começou a crescer mais rapidamente e o primeiro trimestre de 2020 apresentou uma taxa de desemprego de 12,2\% (ALVARENGA; SILVEIRA, 2020). Nos meses seguintes, o Brasil adentra em mais uma recessão econômica acentuada agora pela pandemia. Em síntese, sem adentrar em outras variáveis que também apresentam deterioração nessa década, a economia brasileira não se recuperou nos anos seguintes da recessão dos anos 2015 e 2016. Ademais, apresentava tendências de aprofundamento antes mesmo da pandemia afetar a economia.

O contexto recessivo delineado anteriormente mostra que o governo federal que deveria mudar as políticas austerícidas não vinham dando bons resultados. No entanto, mesmo em meio à forte pandemia, não se vislumbra movimento em direção a políticas anticíclicas. 
Pelo contrário, o governo federal insiste em manter a política que visivelmente não tem dado certo para a maioria da população.

A deterioração das receitas da União fomenta a necessidade de elaboração de políticas e medidas que possam elevar, mesmo que momentaneamente, as receitas para arrefecer o contínuo crescimento do déficit governamental. Dentro desse diapasão, inúmeras ideias, novas e velhas, emanam de diversos grupos econômicos e políticos. O aumento da tributação, a redução dos gastos governamentais, dentre outras propostas emergem ao palco social por meio da reforma tributária, administrativa, política, etc.

Nesse esboço não se pretende adentrar a essas inúmeras propostas, pois essas normalmente dependem de emendas constitucionais ou de lei infraconstitucionais que necessitam seguir diversos princípios e regras que retardam suas vigências, transferindo para 2021 ou depois a possibilidade de se efetivar proporcionando o aumento dos recursos ou a redução dos gastos. Contrapondo-se a tal contexto, pretende-se apresentar, defender e encampar uma proposta já apresentada por diversos juristas, a qual pode, ainda nesse ano, colaborar para elevar os recursos financeiros necessários ao combate da pandemia, aliviando momentaneamente a pressão sobre os fundos públicos.

\section{Ações estatais no combate à pandemia}

Ao fim do primeiro trimestre de 2020, o Brasil é atingido por uma pandemia que já se configurava desde o fim do ano anterior. Ainda no primeiro mês do ano, as notícias sobre o sars-cov-2, nome do novo vírus, assustavam a todos que assistiam aos noticiários internacionais, em particular, as notícias da China. A elevada taxa de contaminação do vírus proporcionou uma disseminação muito rápida no País, o qual não contou com uma política sistêmica contra a pandemia.

O próprio governo federal, na pessoa de quem se encontra na presidência, minimizava o impacto do vírus, não atuando para realizar um isolamento social efetivo, visando obstar a disseminação do vírus, enquanto se encontrava tratamento adequado para a doença. A mudança nos ministros da saúde e a manutenção de um militar sem conhecimentos médicos e de saúde coletiva, como os inúmeros comentários presidenciais, demonstram bem o descaso da União para com a pandemia.

Independentemente da posição e das precárias ações federais, a ação dos governos estaduais instalou um isolamento social sem a densidade necessária para quebrar o ritmo de contágio. Mesmo assim, com taxas de isolamento próximas aos $50 \%$ da população, impediu-se uma catástrofe, afinal, "Se o epidemiologista Marc Lipsitch da Universidade de Harvard estiver totalmente correto, $70 \%$ da população infectada implicaria em mais de sete milhões de mortos, considerando uma mortalidade de $5 \%$ no número de infectados no Brasil." (SILVA; PEREIRA, 2020 p. 12).

O reduzido isolamento social não impediu que o vírus apresentasse taxas de contaminação e de mortalidade estáveis por muito tempo. No mês de maio encontrava-se um crescimento abrupto do número de mortes. Nos meses seguintes, o País apresenta uma estabilidade média que circunda as mil mortes por dia, reduzindo-se apenas em setembro, mas muito lentamente. Ao fim do ano de 2020 uma "nova onda", ou o retorno das elevadas 
taxas de contaminação, provocou o aumento no número de mortes diárias, mantendo o Brasil como o segundo país no mundo em número de mortes por COVID-19.

O isolamento parcial agravou a crise econômica muito mais por sua permanência no tempo do que por sua profundidade. Em outras palavras, o Brasil, por não ter realizado um isolamento sério, manteve seus problemas econômicos por não poder reabrir adequadamente suas atividades econômicas sem reduzir sistematicamente o número de mortos.

Os países que realizaram um lockdown profundo e testes em massa, controlaram mais rapidamente o contágio e puderam retomar as atividades econômicas mais rápido e de forma mais segura como, por exemplo: a Nova Zelândia, a Austrália, o Marrocos e o Vietnam. Entretanto, os países que retardaram o lockdown e não realizaram testes em massa, continuam com elevadas taxas de contaminação e de mortes como, por exemplo: o Brasil, os EUA, o México, a Inglaterra, etc. (BBC, 2020).

Mesmo com atraso e de forma não profunda, o isolamento social realizado pelos governos estaduais colaborou para o retardamento do crescimento abrupto da disseminação virológica. A União pressionada pela expansão do vírus realizou diversas medidas, mesmo que tardiamente, para a contenção do vírus e a mitigação da crise econômica. Inicialmente decretou estado de calamidade, possibilitando que ficassem suspensos os prazos para ajuste das despesas de pessoal e dos limites de endividamento para cumprimento das metas fiscais.

Em outras palavras, o decreto legislativo (BRASIL, 2020a) promulgado possibilitou que a união pudesse liberar a limitação de empenho e ampliar as despesas públicas, adiando o cumprimento da meta fiscal anual. Essa possibilidade está prevista nos artigos 09 e 65 da lei complementar de número 101 de quatro de maio de 2000 que versa sobre a responsabilidade na gestão fiscal (BRASIL, 2020b), também conhecida como Lei da Responsabilidade Fiscal (LRF). Em síntese, o decreto autoriza a União a aumentar seu endividamento sem se preocupar com a persecução do equilíbrio fiscal.

O estado de calamidade pública pode ser compreendido com uma situação atípica, anormal, na qual o poder público, no caso federal, encontra-se comprometido quanto à sua capacidade de solucionar a atipicidade da situação. Quando ocorre a decretação do estado de calamidade, o Estado pode utilizar instrumentos normativos previstos constitucionalmente que em situações de normalidade não são possíveis. A exemplo, os créditos suplementares estabelecidos na emenda constitucional No 106/2020 e no artigo 167 da Constituição Federal de 1988.

Autorizados pelo Decreto Legislativo 06/2020 e pela Emenda Constitucional 106/2020 diversas medidas econômicas foram anunciadas e implantadas pela União, por meio dos diversos ministérios. Destaca-se as ações e medidas relacionadas a:

a) Isenção do Imposto para Operações Financeiras (IOF) para as operações de crédito por noventa dias;

b) Alteração nos prazos de recolhimento das contribuições PIS/PASEP, COFINS, Patronal;

c) Adiamento no prazo de entrega do Imposto de Renda Pessoa Física;

d) Prorrogação no prazo para recolhimento de outros tributos federais;

e) Compra e venda de títulos do Tesouro, por parte do Banco Central;

f) Compra e venda de ativos em mercados secundários; 
g) Concessão de auxílio emergencial;

h) Redução de alíquotas de imposto sobre produtos industrializados e,

i) Outras mais.

Não se nega que, em contexto de pandemia, todas as medidas necessárias para o enfrentamento da covid-19 devem ser utilizadas. No entanto, essas medidas não conseguem sanar o impacto econômico produzido pela crise econômica agravada pelo sars-cov-2. O aumento do desemprego, o fechamento de empresas e o aumento de gastos governamentais provocam forte impacto no equilíbrio das contas públicas. Nesse sentido, o uso de mecanismos normativos existentes que atenuem mesmo que momentaneamente o desequilíbrio das contas públicas é fulcral para o reestabelecimento do equilíbrio fiscal e da capacidade de investimento social.

Os Empréstimos compulsórios se inserem nesse contexto de alívio circunstancial. Os empréstimos compulsórios são instrumentos possíveis e passíveis de utilização rápida, por que já são previstos na Constituição Federal de 1988 e foram estruturados pelo constituinte originário com a pretensão de serem utilizados em situações como a da pandemia do Coronavírus.

\section{EMPRÉSTIMOS COMPULSÓRIOS PARA O COMBATE À COVID-19}

O sistema tributário nacional consiste em um sistema que se estrutura de acordo com a base econômica da incidência. As principais características do sistema tributário nacional, segundo Lobo Torres (2011) são a racionalidade econômica e a facilidade de fiscalização e arrecadação. Embora apresente regressividade significativa, afugentando parcialmente a racionalidade econômica, o sistema tributário nacional permite que em situações adversas, consideradas excepcionais, a União possa instituir empréstimos para além do permitido em contextos normais. Esse mecanismo aproxima o sistema de uma maior racionalidade econômica, afinal salvaguardas tributárias são importantes para tempos inusitados, situações inesperadas, como se pode considerar o caso da pandemia.

Nesse diapasão, a Lei no 5.172 de 1966, conhecida como Código Tributário Nacional (BRASIL, 1966), em seu artigo 15, nos três incisos e um parágrafo único, estabelece as situações nas quais o mecanismo tributário conhecido como empréstimo compulsório pode ser instituído. São três as situações possíveis para as quais a União pode instituir empréstimos compulsórios:

\footnotetext{
I - guerra externa, ou sua iminência;

II - calamidade pública que exija auxílio federal impossível de atender com os recursos orçamentários disponíveis;

III - conjuntura que exija a absorção temporária de poder aquisitivo.

Parágrafo único. A lei fixará obrigatoriamente o prazo do empréstimo e as condições de seu resgate, observando, no que for aplicável, o disposto nesta Lei. (BRASIL, 1966).
}

O empréstimo compulsório é um tributo que foi recepcionado pela Constituição Federal, concebendo-o com o objetivo exclusivo de somente ser exigido em circunstâncias emergenciais, estabelecidas literalmente como em situações de guerras ou de calamidades públicas. A Constituição Federal estabelece explicitamente quem e como deverá instituir o empréstimo compulsório, in verbis: 
Art. 148. A União, mediante lei complementar, poderá instituir empréstimos compulsórios: I - para atender a despesas extraordinárias, decorrentes de calamidade pública, de guerra externa ou sua iminência; (BRASIL, 1988).

A natureza tributária do empréstimo compulsório já se consolidou, independente de alguns poucos estudiosos defenderem a posição contrária. De acordo com Machado Segundo, embora o Supremo Tribunal Federal tenha sumulado "jurisprudência no sentido de que o empréstimo compulsório não é tributo (...) conta com aceitação praticamente unânime em nossa doutrina a tese segundo a qual o empréstimo compulsório é um tributo" (MACHADO SEGUNDO, 2007, p. 120).

A pandemia provocada pelo novo sars-cov-2 implicou na promulgação do decreto de estado de calamidade, previsto para vigorar até 31 de dezembro. Ressalta-se que o vírus não pode ser aceito como fato gerador concreto. No entanto, assume papel de causa justificadora que possibilita a União, por meio de lei complementar, instituir o empréstimo compulsório para custear as despesas inerentes ao combate a COVID-19.

As facilidades criadas pelo empréstimo compulsório se devem ao contexto adverso, o qual não pode ser esquecido, permitindo que se afaste os princípios da anterioridade e da noventena. A legislação também estabelece os limites para o uso do mencionado tributo, principalmente no que se refere ao mesmo estar vinculado à despesa que o fundamentou. Diversos tributaristas advogam pelo uso dos empréstimos compulsórios no atual contexto de crise econômica e pandemia, a ver:

No momento de grave crise de saúde pública, com efeitos sociais e econômicos,
justifica-se, de um ponto de vista técnico-jurídico, a instituição do empréstimo
compulsório para fazer face a despesas com a calamidade instaurada, seja para
investir em saúde para tutelar a sociedade, seja ainda para investir na recupera-
ção da economia. Essas destinações, entretanto, têm de constar expressamen-
te por se tratar de hipótese de tributo vinculado à despesa pública. Ademais,
haveria de se aplicar as políticas tributárias em conformidade com a ordem
econômica, evitando-se incoerências do sistema com sérios efeitos sociais e
econômicos. A intersecção entre mecanismos fiscais, com controle adequado da
despesa pública e o equilíbrio do mercado, é um caminho sem volta para a solu-
ção dos tantos problemas que afligem o país (ZARANZA; ELALI, 2020, p. 05).

Arruda de Andrade e Araújo Branco, mesmo sem discordarem do uso do empréstimo compulsório, mostram-se cautelosos, questionando sobre a efetiva necessidade de uso do mesmo, dado que ainda não se tinha utilizado todo o arsenal tributário disponível para enfrentamento de situações adversas como a pandemia. Para os autores:

(...) é possível apontar medidas prévias à necessidade da instituição do empréstimo e, como se pode perceber a partir de experiências anteriores com tal espécie tributária, tampouco adianta ao governo aprovar um tributo natimorto, cuja cobrança vai ser inviabilizada pelo Poder Judiciário, caso não obedeça ao regime jurídico correto, pois a política pública deve ser consistente com as normas vigentes do país (ANDRADE; ARAÚJO BRANCO, 2020, p. 04). 
Em alguns aspectos as vantagens do uso do empréstimo compulsório são evidentes. Como o empréstimo compulsório não padece do princípio da anterioridade (vacatio legis) e da noventena, é possível instituí-lo e cobrá-lo no mesmo exercício. Uma das bases para cobrança do empréstimo compulsório pode se dar a partir dos dados alusivos ao patrimônio dos contribuintes que estão na abrangência da atuação da Receita Federal. Essa instituição poderia registrar nos seus computadores, a exigência do empréstimo compulsório, não dependendo de novas declarações a serem apresentadas.

A Receita Federal brasileira poderia, por meio de notificações, lançar de ofício esse tributo. Esse fato se revela como uma vantagem, no sentido de que se torna muito célere a instituição e a cobrança, pois após a aprovação pelo Congresso Nacional, a exigência poderá ser efetivada prontamente.

Um outro aspecto importante e vantajoso se refere ao fato de que o constituinte originário não engessou os empréstimos compulsórios, pois não deixou estabelecido na Constituição Federal os prováveis fatos geradores do empréstimo compulsório ou mesmo o campo tributário de incidência. Assim, concedeu-se ao legislador uma ampla liberdade para delinear os fatos ou as ocorrências do objeto da incidência tributária, desde que sejam efetivados por meio de lei complementar (BOMTEMPO, SILVA, 2020, p. 07).

Poucos foram os juristas contrários ao uso do empréstimo compulsório. A exemplo, Evandro Azevedo Neto, ao advogar que "a situação atual não permite, a princípio, a instituição de nova carga tributária por meio de empréstimo compulsório diante da evidente ausência de necessidade de tal recurso" (AZEVEDO NETO, 2020, p. 04). Essa defesa, realizada no fim do mês de março de 2020 demonstra que provavelmente o autor não tinha dimensão dos possíveis impactos sociais de uma pandemia. Não há de se rejeitar a ideia de que talvez poucos cientistas tivessem a real percepção da profundidade e gravidade da pandemia.

Azevedo Neto não veda totalmente a possibilidade de uso dos empréstimos compulsórios, no entanto defende que os mesmos somente sejam utilizados quando ocorrer efetivamente a "(...)sua comprovação, por meio de exercício amplo de publicidade à sociedade, (...)" pois tão somente assim, por meio de sua "comprovação de necessidade, ter-se-ia, a nosso ver, existentes os requisitos para tal tributação na forma do artigo 148, I, da constituição." (AZEVEDO NETO, 2020, p. 05).

O fato é que as evidências de uma crise econômica que se prefigurava antes da pandemia, implicavam em uma recessão econômica e a pandemia somente aprofundaria essa recessão, tornando imprescindível medidas de diversas ordens, inclusas as tributárias, para mitigar a crise social, econômica e de saúde.

A Emenda Constitucional 95, também conhecida por PEC do Teto dos gastos públicos, implicou em limites aos gastos públicos. No entanto, é razoável aceitar que em um contexto de pandemia mundial, com elevado número de contaminações e mortes, contingenciar recursos nas áreas de saúde é, no mínimo, inaceitável, para não falar em desumanidade. O governo federal, no ano de 2020, destinou no orçamento mais de 187 bilhões para a área de atuação em saúde, no entanto somente executou pouco mais de $80 \%$ desses recursos ou aproximadamente 150 bilhões (BRASIL, 2021).

Aparentemente, ter-se-ia recursos para serem utilizados, mas dado o caos do sistema de saúde durante a pandemia, com falta de equipamentos, medicamentos, equipes médicas, 
etc., mesmo os 187 bilhões destinados seriam pouco para sanar minimamente as necessidades de atuação em saúde, considerando a pandemia. Ressalte-se que o crescimento da dívida pública geral do governo alcança algo próximo a $96 \%$ do PIB, representando um crescimento de mais de 20 pontos percentuais em relação a 2019. O déficit primário atinge mais de $12 \%$ do PIB e a dívida líquida do setor público do governo alcança, em 2020, mais de $68 \%$ do PIB (BRASIL, 2020). Nesse sentido, considerando que a equalização da Pandemia em solo nacional torna-se urgente para o pleno retorno das atividades econômicas, o aumento das receitas governamentais para custear as despesas com saúde, podem colaborar para o equacionamento das contas públicas em 2021.

Os efeitos da crise causada pela pandemia do novo coronavírus levaram o governo brasileiro a ter a menor arrecadação de tributos em 14 anos. Em abril, foram arrecadados 101,2 bilhões de reais, uma queda forte de $29 \%$ sobre o mesmo período de 2019 e o pior resultado para o mês desde 2006, de acordo com os dados divulgados nesta quinta-feira, 21, pela Receita Federal (KIANEK, 2020, p. 01).

Não há como se descartar que a pandemia, atualmente com mais de 230 mil mortos e milhões de contaminados não se caracterize como calamidade pública. Nesse sentido, dado o processo econômico recessivo que a economia brasileira perpassa desde 2015, o elevado e crescente déficit público e a insuficiência de recursos públicos para atender as novas despesas com saúde, urge que a União providencie novos recursos para fazer frente às novas e inesperadas despesas. A noção de despesa extraordinária decorrente de calamidade pública implica o reconhecimento do esgotamento dos fundos públicos, perceptível até mesmo ao público leigo.

A subsistência de valores até então não utilizados não impediria a criação do tributo em questão, dado que existe a necessidade de novos recursos (vide crescimento do endividamento público) e que a não utilização plena de todos os recursos ainda existentes se deve à ineficiência no uso dos mesmos, para não mencionar a suposição de não uso dos recursos com fins de contingenciamento visando redução do déficit público em meio a uma pandemia.

O empréstimo compulsório, mesmo se constituindo em novo tributo, atenuaria os impactos financeiros da pandemia e reduziria, no curto prazo, o endividamento público, mesmo que elevando-os no longo prazo. Mas no longo prazo a economia já terá se recuperado, possibilitando ao Estado os recursos para estorno dos empréstimos compulsórios.

O tributo em comento poderia ter sua exação nos segmentos que apresentaram crescimento durante a pandemia e em clássicos segmentos econômicos de produção de bens de luxo, a exemplo: os serviços de delivery; produtos para home office; eletrônicos; automóveis de luxo, etc. Dado o avanço tecnológico consubstanciado na cobrança do ICMS pela nota fiscal eletrônica, poder-se-ia mais facilmente exigir o tributo, como também a devolução do mesmo em um futuro próximo. O desenvolvimento tecnológico digital atual permite celeridade e eficiência na cobrança e na devolução do tributo compulsório. A despeito da taxa de desemprego ser elevada e o país contar com aproximadamente 14 milhões de desempregados, o ano de 2020 terminou com um pequeno incremento no emprego formal, frente ao ano de 2019. 
Nesse diapasão, vislumbra-se espaço para um tributo como o empréstimo compulsório que, diferente dos demais, será estornado nos anos seguintes. As maiores dificuldades são políticas, as quais podem ser removidas via conscientização da gravidade epidemiológica vivida pelo país.

Equívocos e ineficiências na exação desse tributo no passado não implicam que tenham que ocorrer atualmente. O desenvolvimento tecnológico e político inserto na sociedade brasileira possibilita uma melhor adequação do tributo contemporaneamente.

\section{CONSIDERAÇões FINAIS}

Os tributaristas brasileiros digladiaram-se acerca da natureza jurídica dos empréstimos compulsórios. Ao fim do embate, é preciso compreender que a doutrina que se consolidou acerca do objeto em tela, fundamenta-se na tese de que os empréstimos compulsórios são tributos. Esse fundamento visa a proteção dos contribuintes contra o leviatã ou, em outras palavras, visa proteger o contribuinte contra os abusos tributários do Estado.

Em passado recente, o uso dos empréstimos compulsórios implicou em desrespeito às normas vigentes por parte do próprio Estado que não restituiu a tempo os valores emprestados. Configurado como tributo e estabelecido por lei, a nova legislação constitucional permite uma maior segurança para o contribuinte. Não nos cabe aqui apresentar especificamente os fatos geradores nos quais poder-se-ia instituir o empréstimo compulsório, dado que são inúmeras as possibilidades que dependem do debate e deliberação parlamentar. Cabe-nos apenas demonstrar a efetiva possibilidade jurídico-econômica, como também a necessidade do empréstimo devido à materialização de uma crise econômica agravada pela pandemia. O empréstimo compulsório se materializa, assim, como um meio viável tanto nas dimensões técnicas e econômicas quanto nas jurídicas.

Nesse diapasão de maior segurança, legitimidade e legalidade, o empréstimo compulsório, enquanto tributo, possibilita uma "válvula de escape" para situações inesperadas e que se caracterize como calamidade gerando crises financeiro-econômicas que afetem as finanças estatais exigindo intervenção célere por parte do Estado que pode acionar esse mecanismo.

Atualmente, embora existam discordâncias entre os juristas acerca do uso do mecanismo tributário em tela, para o combate à pandemia, é para situações como essas que os empréstimos compulsórios foram estruturados.

\section{REFERÊNCIAS}

ALVARENGA, D., SILVEIRA, D. Desemprego sobe para $12,2 \%$ no $1^{\circ}$ trimestre e atinge 12,9 milhões. ECONOMIA. G1.com.br Disponível em: $<<\underline{\text { https://g1.globo.com/econo- }}$ mia/noticia/2020/04/30/desemprego-sobe-para-122percent-em-marco-e-atinge-129-milhoes.ghtml $>>$ Acesso em 03 de setembro de 2020.

, Brasil cria 644 mil empregos formais em 2019, melhor resultado em 6 anos. Economia. G1.com.br. 24 de janeiro de 2020. Disponível em: $<<$ https://g1.globo.com/eco- 
nomia/noticia/2020/01/24/brasil-cria-empregos-644-mil-empregos-formais-em-2019-melhor-resultado-em-6-anos.ghtml >> Acesso em 03 de setembro de 2020.

ARRUDA DE ANDRADE, J. M.; ARAÚJO BRANCO, L. O. de, Precisamos de um empréstimo compulsório para combater a pandemia? CONSULTOR JURIDICO. 19 de abril de 2020. Disponível em: $<<$ https:/www.conjur.com.br/2020-abr-19/precisamos-emprestimo-compulsorio-combater-pandemia $>>$ Acesso em 10 de setembro de 2020.

AZEVEDO NETO, E. Calamidade pública justifica novo empréstimo compulsório? CONSULTOR JURIDICO. 26 de março de 2020. Disponível em:<< https://www.conjur.com. br/2020-mar-26/evandro-azevedo-calamidade-publica-justifica-emprestimo-compulsorio $>>$ Acesso em 11 de setembro de 2020 .

BBC. Coronavírus: os melhores e os piores países para se estar na pandemia. 2020. Disponível em: $<<$ Coronavírus: os melhores e os piores países para se estar na pandemia - BBC News Brasil $>>$ Acesso em: 07 de fevereiro de 2021.

BOMTEMPO, L. G. ; SILVA, M. Empréstimo compulsório: mais recursos na contenção do coronavírus. Opinião. CONSULTOR JURIDICO. 30 de março de 2020. Disponível em: <<https://www.conjur.com.br/2020-mar-30/opiniao-emprestimo-compulsorio-contencao-coronavirus $>>$ Acesso em 10 de setembro de 2020.

BRASIL, Lei No 5.172, de 25 de outubro de 1966. Senado Federal. Brasília. 1966. Disponível em: $<<$ http://www.planalto.gov.br/ccivil 03/leis/15172compilado.htm $>>$ Acesso em 08 de setembro de 2020 .

, Constituição da República Federativa do Brasil. 1988. Disponível em: $<<\underline{\text { http:// }}$ www.planalto.gov.br/ccivil_03/constituicao/constituicao.htm $>>$ Acesso em 02 de setembro de 2020.

, LEI 13.467 de 13 de julho de 2017. Senado Federal. Brasília. Disponível em: $<<$ http://www.planalto.gov.br/ccivil 03/ ato2015-2018/2017/lei/113467.htm\#: :text=Altera $\% 20 \mathrm{a} \% 20 \mathrm{C}$ onsolida $\% \mathrm{C} 3 \% \mathrm{~A} 7 \% \mathrm{C} 3 \% \mathrm{~A} 3 \mathrm{o} \% 20 \mathrm{das} \% 20 \mathrm{Leis}, \% \mathrm{C} 3 \% \mathrm{~A} 0 \mathrm{~s} \% 20$ novas $\% 20$ rela $\% \mathrm{C} 3 \% \mathrm{~A} 7 \% \mathrm{C} 3 \% \mathrm{~B} 5 \mathrm{es} \% 20 \mathrm{de} \% 20$ trabalho. $>$ Acesso em 03 de setembro de 2020.

. Decreto legislativo N0 06, de 20 de março de 2020a. Senado Federal. Brasília. 2020. Disponível em: << https:/www.in.gov.br/en/web/dou/-/decreto-legislativo-249090982>> Acesso em 07 de setembro de 2020.

, Lei Complementar $\mathbf{N}^{0}$ 101, de 04 de maio de 2000b. Senado Federal. Brasília, 2000, Disponível em: $<$ http://www.planalto.gov.br/ccivil 03/leis/lcp/lcp101.htm $>>$ Acesso em 07 de setembro de 2020. 
, Relatório Quadrimestral de Projeções da Dívida Pública 2020 - No 3, Ministério da Economia, Secretaria Especial de Fazenda, Secretaria do Tesouro Nacional, Brasília: Secretaria do Tesouro Nacional, outubro, 2020, número 3. Disponível em: $<<2020-10-30-$ rpdp.pdf (www.gov.br) $>>$ Acesso em 07 de fevereiro de 2021.

, Portal da transparência. Controladoria Geral da União. Brasília, 2021. Disponí-

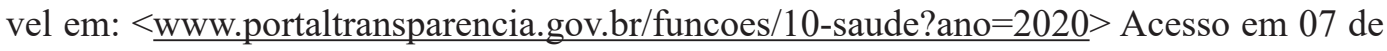
fevereiro de 2021.

CAETANO, R; JANKAVSKI, A.; NOGUEIRA, L. A. À espera do impeachment. ISTO É. DINHEIRO, Ed. 1186, 28 de agosto de 2017.<<https:/www.istoedinheiro.com.br/noticias/ economia/20160819/espera-impeachment/405321 > Acesso em 03 de setembro de 2020.

IBGE. Sistema de contas Nacionais Trimestrais -SCNT. Brasília, 2020. Disponível em: $<<$ Sistema de Contas Nacionais Trimestrais - SCNT | IBGE $>>$ Acesso em: 15 setembro de 2020 .

KIANEK, Alessandra. O rombo bilionário do governo causado pela Covid na arrecadação de tributo. Veja, sem local de publicação, 21 de maio de 2020. Seção Economia. N.P. Disponível em: $<<$ https://veja.abril.com.br/economia/o-rombo-bilionario-do-governo-na-arrecadacao-de-tributo-causado-pela-covid/>> . Acesso em 0 de fevereiro de 2021.

MACHADO SEGUNDO, H. de BRITO, Natureza jurídica do empréstimo compulsório. Revista do Curso de Mestrado em direito da UFC. 2007. Disponível em $<<$ Vista do NATUREZA JURÍDICA DO EMPRÉSTIMO COMPULSÓRIO (ufc.br) >> Acesso em 10 de setembro de 2020 .

MARTELLO, A. Nova lei trabalhista deve gerar mais de 6 milhões de empregos, diz Meirelles. Economia. G1.com.br. 30 de dezembro de 2017. Disponível em:<<https://g1.globo. com/economia/noticia/nova-lei-trabalhista-vai-gerar-mais-de-6-milhoes-de-empregos-diz-meirelles.ghtml >> Acesso em 03 de setembro de 2020.

MOTA, C. V. PIB: Por que 2019 frustrou mais uma vez as expectativas de crescimento da economia. NEWS/BRASIL. bbc.com, 04 de março de 2020. Disponível em: $<<\underline{\text { https:// }}$ www.bbc.com/portuguese/brasil-51714002 >> Acesso em 03 de setembro de 2020.

SILVA, C. C. F. da; PEREIRA, W. E. N. A Pandemia de COVID-19 e o Nível de Emprego nos Municípios do Rio Grande do Norte - Boletim GEPETIS n.1 2020. Disponível em: $\quad<<$ https://www.researchgate.net/publication/342693621_A Pandemia de COVID-19 e o Nivel de Emprego nos Municipios do Rio Grande do Norte - Boletim n1 de 2020 $>>$ Acesso em 08 de setembro de 2020.

TORRES, R. L. Noção de sistema tributário. IN: MARTINS, I. G. da S.; NASCIMENTO, 
V. do; MARTINS, R. G. da S. (Coord.), Tratado de direito tributário, volume 1, São Paulo :Saraiva, 2011.

ZARANZA, E.; ELALI, A. Considerações sobre propostas de mudanças tributárias em face da crise. CONSULTOR JURIDICO. 14 de abril de 2020. Disponível em: $<<\underline{\text { https:// }}$ www.conjur.com.br/2020-abr-14/elali-zaranza-mudancas-tributarias-face-crise $>>$ Acesso em 09 de abril de 2020.

\section{DAdos dos AUTORES}

\section{William Eufrasio Nunes Pereira}

Bacharel em direito e economia. Especialista em Gestão dos Recursos Humanos. Mestre em economia e mestrando em direito. Doutor em ciências Sociais. E-mail: wenpereira2014@gmail.com

\section{André de Souza Dantas Elali}

Mestre em Direito Político e Econômico pela Universidade Mackenzie/SP e Doutor em Direito Público pela Faculdade de Direito do Recife com Estágio e Bolsa de Pesquisa no Max-Planck-Institüt für Steuerrecht, em Munique, Alemanha. E-mail: andreelali@gmail.com

Submetido em: 6-11-2020

Aceito em: 5-3-2021 